\title{
Morphology, Characterization and Distribution of Retinal Photoreceptors in the South American (Lepidosiren paradoxa) and Spotted African (Protopterus dolloi) Lungfishes
}

\author{
Audrey M. Appudurai ${ }^{1,2 *}$, Nathan S. Hart ${ }^{2,3,4}$, lonat Zurr ${ }^{1}$ and Shaun P. Collin ${ }^{2,3}$ \\ ${ }^{1}$ SymbioticA, School of Anatomy, Physiology and Human Biology, The University of Western Australia, Crawley, WA, \\ Australia, ${ }^{2}$ The Neuroecology Group, School of Animal Biology, The University of Western Australia, Crawley, WA, Australia, \\ ${ }^{3}$ UWA Oceans Institute, The University of Western Australia, Crawley, WA, Australia, ${ }^{4}$ Department of Biological Sciences, \\ Macquarie University, North Ryde, NSW, Australia
}

\section{OPEN ACCESS}

Edited by: Ronald Hamilton Douglas, City University London, UK

Reviewed by: Helena J. Bailes, The University of Manchester, UK Hans Joachim Wagner,

University of Tübingen, Germany

*Correspondence: Audrey M. Appudurai audrey.bester00@gmail.com

Specialty section: This article was submitted to Behavioral and Evolutionary Ecology,

a section of the journal

Frontiers in Ecology and Evolution

Received: 17 February 2016 Accepted: 10 June 2016 Published: 24 June 2016

Citation: Appudurai AM, Hart NS, Zurr I and Collin SP (2016) Morphology, Characterization and Distribution of Retinal Photoreceptors in the South American (Lepidosiren paradoxa) and Spotted African (Protopterus dolloi) Lungfishes. Front. Ecol. Evol. 4:78. doi: 10.3389/fevo.2016.00078
Lungfishes are the closest living relatives of the ancestors to all terrestrial vertebrates and have remained relatively unchanged since the early Lochkovin period (410 mya). Lungfishes, therefore, represent a critical stage in vertebrate evolution and their sensory neurobiology is of considerable interest. This study examines the ultrastructure of the retina of two species of lungfishes: the South American lungfish, Lepidosiren paradoxa and the spotted African lungfish, Protopterus dolloi in an attempt to assess variations in photoreception in these two ancient groups of sarcopterygian (lobe-finned) fishes. In juvenile $P$. dolloi, the retina contains one rod and two cone photoreceptor types (one containing a red oil droplet), while only one rod and one cone photoreceptor type is present in adult $L$. paradoxa. Both species lack double cones. The large size and inclusion of oil droplets in both species apart from one of the cone photoreceptor types in P. dolloi suggests that $L$. paradoxa and $P$. dolloi are adapted for increasing sensitivity. However, the complement of photoreceptor types suggests that there may be a major difference in the capacity to discriminate color (dichromatic and monochromatic photoreception in P. dolloi and L. paradoxa, respectively). This study suggests that the visual needs of these two species may differ.

Keywords: dipnoi, color vision, photoreceptors, oil droplets, sensitivity, lungfishes

\section{INTRODUCTION}

The South American (Lepidosiren paradoxa) and spotted African (Protopterus dolloi) lungfishes are dipoan fishes that belong to the order Lepidosireniformes. Lungfishes, including Neoceratodus forsteri (order Ceratodontiformes) from Australia diverged from the main vertebrate stock $\sim 410$ mya and along with the coelacanth (Latimeria chalumnae), encompass the surviving lobe-finned fishes (Sarcopterygii; Bemis et al., 1987; Collin, 2010; Clack et al., 2011). Lungfishes have the ability to breathe dissolved and atmospheric oxygen through gills and "primitive" lungs, respectively. 
Linked to humans by being the closest living relatives to the tetrapods (Brinkmann et al., 2004; Amemyia et al., 2013), they are vital to the study of the evolution of vision in terrestrial animals.

The South American lungfish resides in the neotropics of South America and has the most extensive distribution of all lungfish species (Fonesca de Almeida-Val et al., 2011). Its range extends through Argentina, Bolivia, Colombia, Brazil, Paraguay, Venezuela, and French Guiana, and although it is found in the Parana-Paraguay River system, it is preferentially located within the Amazon River basin (Fonesca de Almeida-Val et al., 2011). All African lungfishes are endemic to the river systems of a large part of the African continental landmass, and $P$. dolloi primarily inhabits the Congo River basin.

Previous studies of $N$. forsteri, considered the most basal of all lungfish species (Kemp and Molnar, 1981; Bailes et al., 2006), show that at least some species of lungfish possess a complex tri- or tetra-chromatic color vision resembling that of diurnal vertebrates such as birds and reptiles. This suggests that several of the ocular characteristics lungfishes possess may have evolved in shallow water before the transitioning onto land (Collin, 2010). One such characteristic is the presence of corneal surface microprojections present in terrestrial vertebrates and $N$. forsteri and may have evolved in order to provide clear aerial vision for those lungfishes that aestivate (Collin and Collin, 2001).

Previous anatomical studies have shown that the eyes of lungfishes possess different morphological types of retinal photoreceptor, demonstrating that they have the neural machinery to process color (Walls, 1942; Pfeiffer, 1968; Ali and Anctil, 1973). N. forsteri is the only species in which the retina has been studied in detail (Marshall, 1986; Tokita et al., 2005; Bailes et al., 2006). Up to five spectrally distinct types of large retinal photoreceptors have been found in $N$. forsteri: one type of $\operatorname{rod}\left(\lambda_{\max } 540 \mathrm{~nm}\right)$ and four types of cones (UVS $\lambda_{\max } 366$ $\mathrm{nm}$, SWS $\lambda_{\max } 479 \mathrm{~nm}$, MWS $\lambda_{\max } 558 \mathrm{~nm}$, and LWS $\lambda_{\max }$ $623 \mathrm{~nm}$ ). UVS cones are only found in the retinas of juvenile $N$. forsteri, suggesting that sensitivity to ultraviolet light is lost during maturation (Bailes et al., 2006; Hart et al., 2008). The possession of four types of cones in juvenile lungfishes implies that they have the potential for tetrachromatic vision, which is perhaps unusual for an animal that has previously been considered predominantly nocturnal or crepuscular (Dean, 1906, 1912; Grigg, 1965; Kemp, 1986). To date, the retinae of the South American and spotted African lungfishes have only been superficially characterized by using light microscopy and both species are thought to possess one type of rod and at least two types of cone, suggesting that these species may also have the capacity for color vision. $P$. dolloi appears to possess both single and double cones, while L. paradoxa and $N$. forsteri possess only single cones (Ali and Anctil, 1973; Bailes et al., 2006).

P. dolloi and L. paradoxa possess oil droplets in both their cone and rod photoreceptors (Kerr, 1902; Walls, 1942; Pfeiffer, 1968; Ali and Anctil, 1973), whereas $N$. forsteri only possesses colorless oil droplets in their SWS cones, colored yellow pigment in their MWS cones and red oil droplets in their LWS cones (Bailes et al., 2006). Colorless oil droplets are found in marsupial mammals which are generally nocturnal, crepuscular or cathemeral and are thought to improve light gathering ability and thus, overall sensitivity. Colored oil droplets act as miniature spectral filters within each photoreceptor and, by narrowing the spectral sensitivity function of the photoreceptors, are thought to improve color discrimination by reducing overlap with adjacent spectral classes of cone (Vorobyev et al., 1998; Hart et al., 2008). The presence of colored oil droplets in the lungfish retina is surprising because these characteristics are found only in strongly diurnal animals such as birds and reptiles, and the spotted African and South American lungfishes occupy swamps and lakes that consist of lentic (stagnant) water bodies associated with poor visibility, weedy vegetation, low oxygen content, and seasonal drying (Greenwood, 1986; Mlewa et al., 2011).

In most animals with image-forming eyes, the densities of photoreceptor cells are not uniform across the retina (Collin, 1999), and usually reflects key features of their visual behavior in respect to their physical environment, as well as determining the visual acuity or spatial resolving power of their eyes. The areas that exhibit an increase in photoreceptor density in the $N$. forsteri retina vary as the fish matures (Bailes et al., 2006). The highest density of rods in the juvenile and sub-adult $N$. forsteri lie in the temporal retina, implying an increase in retinal sensitivity in the frontal visual field. As the fish matures, this temporal specialization becomes two areas of increased rod density (with the second high density region situated in the central retina in adults), to form a weak horizontal band across the retinal meridian. In general, the increased density of cone photoreceptors is predominantly in the dorso-temporal retina and the ventral-nasal retina in all growth stages of $N$. forsteri, indicating a downwardly directed visual axis (Bailes et al., 2006). The topographic specializations in L. paradoxa or Protopterus spp. are not yet known.

Both Protopterus spp. and L. paradoxa undergo aestivation. Aestivation can be described as a "light" state of dormancy, characterized by inactivity and a lowered metabolic rate that can be quickly reversed if the right conditions are met. This process enables these ancient fishes to avoid damage from high temperatures and desiccation during the dry season without leaving the swamps for permanent water, like some teleost fishes (Greenwood, 1986). In their respective burrows, both species of lungfishes remain until the onset of the wet season, which may be for up to 8 months. It is not known if vision plays a significant role in their lifestyle during this aestivating phase, since normal metabolic function and activity is not triggered until the wet season begins.

Consequently, the visual system in lungfishes is something of a conundrum. It appears the habitat and lifestyle of $P$. dolloi and L. paradoxa are also not heavily reliant on their visual system. Little is known about the visual behavior of any lungfish species, and it has been stated a number of times that vision does not contribute heavily to their lifestyle, at least in prey capture and navigation (Owen, 1840; Carter and Beadle, 1930; Johnels and Svensson, 1954; Curry-Lindahl, 1956; Pfeiffer, 1968; Greenwood, 1986). The photic habitat of the swamps and rivers of the Amazon and Congo allows for poor visibility, with a substantial amount of sediment and mineral deposits contributing to turbid, and therefore relatively dim, underwater light environments. Combined with their aestivating behavior, where they remain 
dormant for most of the year, it would appear that vision does not play an essential role in survival. However, the complex visual apparatus of the lungfish eye, including a well-developed lens and active accommodatory apparatus, the presence of colored oil droplets and the presence of four spectral types of cone photoreceptor in N. forsteri (Bailes et al., 2006, 2007), suggests that color vision is more important to lungfishes than previously thought.

This study fills crucial knowledge gaps regarding the visual capabilities of $P$. dollo $i$ and L. paradoxa by characterizing specific photoreceptor types based on their size, ultrastructure and topographic distribution. There have only been two published papers specifically focused on the retina of $P$. dolloi (Pfeiffer, 1968) and L. paradoxa (Ali and Anctil, 1973) using retinal tissue prepared in paraffin wax for light microscopy. This will be the first report on the retinal photoreceptors of $P$. dolloi and L. paradoxa examining resin embedded retinal tissue, enabling the ultrastructure of the photoreceptors to be described at the level of the transmission electron microscope.

The study reveals that based on morphology; there are at least three different photoreceptor types in juvenile $P$. dolloi, and one rod and one cone photoreceptor type in L. paradoxa. The topographical distribution of a cone photoreceptor type containing a red oil droplet is also presented for juvenile $P$. dolloi. This suggests that juvenile $P$. dolloi have the potential for dichromatic color vision, and L. paradoxa may be the only lungfish species without the potential for color vision. These findings provide novel data that contributes to our understanding of the visual experience of $P$. dollo $i$ and L. paradoxa, and provide insight to the role vision plays in their behavioral ecology.

\section{METHODS}

\section{Samples}

All lungfish eye samples were donated by international collaborators who had obtained the animals through the international pet trade. Eyes from three juvenile $P$. dolloi (total length, TL 20.6, 20.2, and $24 \mathrm{~cm}$; eye codes Pd5L, Pd3R, and Pd4R) were obtained from Dr. Guido Westhoff from the University of Bonn, Germany. Two eyes from an adult L. paradoxa (TL $96 \mathrm{~cm}$ ) were obtained from Prof. Glenn Northcutt from the University of California, San Diego (UCSD), USA. All animals were light adapted and sacrificed during daylight hours. Following enucleation, the lens of L. paradoxa was removed. However, due to the small size of the $P$. dolloi eyes, the lens was not removed and the eyes were immersion fixed in toto. All samples were preserved in Karnovsky's fixative (2\% paraformaldehyde, $2.5 \%$ glutaraldehyde in $0.1 \mathrm{M}$ sodium cacodylate buffer, $\mathrm{pH}$ 7.4) prior to being transported to the University of Western Australia.

\section{Light and Electron Microscopy}

All eye samples were processed for both light and electron microscopy to examine the morphology of the photoreceptors within the retina of $P$. dolloi and L. paradoxa. Due to the fragility of the photoreceptors, the retina was not removed from the eye cup, but a significant amount of connective tissue surrounding the eye was removed prior to embedding in Procure-Araldite (ProSciTech). However, under some circumstances, the retina of L. paradoxa still peeled away from the underlying pigment epithelium, subsequently damaging the photoreceptors. The eyecup was then postfixed for $1 \mathrm{~h}$ with $1 \%$ osmium tetroxide in $0.15 \mathrm{M}$ phosphate buffer, dehydrated through an alcohol and propylene oxide series and infiltrated with Procure-Araldite (ProSciTech). For light microscopy, semi-thin $(1 \mu \mathrm{m})$ sections were cut with a glass knife using a LKB Bromma Ultratome NOVA. Semi-thin sections were then deplastinated with a wash in a solution of sodium ethoxide, $70 \%$ alcohol and double distilled $\mathrm{H}_{2} \mathrm{O}$ and stained with $4 \%$ Toluidine blue. Light micrographs were taken using an Olympus camera (Model DP70) mounted on an Olympus compound light microscope (Model BX50F4). For transmission electron microscopy, ultrathin sections $(110 \mathrm{~nm})$ were cut using a diamond knife and mounted on a 200 mesh copper grid. Examination of ultrathin sections was done using a JEOL 2100 transmission electron microscope operating at 120 $\mathrm{kV}$ and photographed using an 11 megapixel Gatan Orius digital camera.

\section{Assessment of Photoreceptor Dimensions and Morphology}

All measurements were conducted from digital images of light and electron micrographs using ImageJ 1.46r (National Institute of Health, USA). Three quarters of the eye were sampled from each individual, and included the nasal/dorsal and nasal/ventral quadrants of the eye. To allow for comparison between photoreceptor cells, the outer segment diameter was measured at the base, and the ellipsoidal diameter was measured at the widest point. Shrinkage of $L$. paradoxa eye tissue could not be determined due to unrecorded pre-fixation dimensions. However, measurements of the $P$. dolloi eye tissue prefixation revealed shrinkage (post-fixation) to be $6.3 \%$ using the methodology outlined by Bailes et al. (2006). All measurements are quoted as mean \pm standard deviation (SD) followed by sample size $(n)$.

\section{Preparation of Retinal Wholemount}

In order to analyse the topographic distribution of the large red oil droplet containing cone photoreceptor type, one retina of a juvenile $P$. dolloi $(24.3 \mathrm{~cm}$ in TL) was dissected and fixed in $4 \%$ paraformaldehyde in $0.1 \mathrm{M}$ phosphate buffer (PFA, $\mathrm{pH}$ 7.4). A retinal wholemount was prepared according to standard protocols (Stone, 1981; Coimbra et al., 2006). The flattened retina was then rinsed in phosphate buffer, mounted onto a subbed glass slide with the photoreceptor layer facing upwards in $100 \%$ glycerol, and sealed. The cones could be distinguished from rods (based on their size and tapered outer segment) by changing the fine focus on the microscope at a magnification of x1000 using a 1.40 numerical aperture (NA) oil immersion objective.

\section{Stereological Analysis and Construction of a Topographic Map}

The topographic distribution of the oil droplet containing photoreceptor in P. dolloi was assessed using the modified optical fractionator technique detailed in Coimbra et al. (2009). Using 
StereoInvestigator software (Microbrightfield Inc., USA) on a Windows 7 PC connected to a compound microscope (Olympus BX50) equipped with a motorized stage (MAC200, Ludle Electronic Products, USA) and digital video camera (MicroFIRE, OPTRONICS), the outline of the retinal wholemount was digitized using a $\mathrm{x} 4$ objective (NA 0.13). Using a x100 oil immersion objective (1.40 NA), all red cone photoreceptors in the retinal wholemount were counted. The retinal outline and cell count data were exported as an Extensible Markup Language (.xml) format file and analyzed using the open source statistical program R v2.15.1 (R Foundation for Statistical Computing, 2012) modified with additional packages and a custom script according to Garza-Gisholt et al. (2014) to construct the retinal topographical map.

\section{RESULTS}

Photoreceptor Characterization and Morphology of L. paradoxa. The photoreceptors of adult L. paradoxa are large and tightly packed. Based on morphological characteristics at both the light and electron microscope levels and dimensions of the photoreceptors (Table 1), there is one rod and at least one cone photoreceptor type in adult L. paradoxa (Figure 1A). Both rods and cones possess oil droplets and were distinguished from each other by their synaptic terminals. Rods maintained spherule synaptic terminals and cones possessed pedicles with an increased number of synaptic ribbons. No double cones were observed. Oil droplets visible in the electron micrographs of photoreceptors appear to contain electron-dense material (Figure 1B). All light micrograph images do not contain inclusions within the oil droplets (Figure 1A). We believe that the electron dense inclusions in the electron micrographs may be artifacts, but frozen sections were not taken to view these oil droplets using light microscopy.

The rod photoreceptor is large, and possesses a tapered outer segment that is usually shorter in length than the outer segment of the cones $(8.0 \pm 1.4 \mu \mathrm{m}, n=13$, with a basal diameter of $10.1 \pm 0.8 \mu \mathrm{m}, n=14$; Figure 1A). The ellipsoid contains a larger oil droplet than the cones $\left(268.7 \pm 51.0 \mu \mathrm{m}^{2}, n=12\right.$ in rods, compared to $82 . \pm 22.0 \mu \mathrm{m}^{2}, n=7$ in cones), with the majority of mitochondria and the paraboloid located closer to the nucleus (Figure 1A). It is more difficult to differentiate rods and cones in L. paradoxa in comparison to N. forsteri and P. dolloi. However, rods can be identified by the presence of incisures in the edges of the outer segment disks and a more cylindrical outer segment.
Like all other species of lungfishes described, the cones are large $(13.6 \pm 2.8 \mu \mathrm{m}$ outer segment length; $n=15$, and $10.5 \pm 1.5$ $\mu \mathrm{m}$ ellipsoid diameter; $n=10$ in a $96 \mathrm{~cm}$ individual) and contain one oil droplet (mean diameter $82.8 \pm 21.9 \mu \mathrm{m}^{2}, n=7$ ) within the ellipsoid. There are no additional oil droplets embedded within the mitochondria in the ellipsoid region in the cones (Figure 1B). The mitochondria are distributed more centrally within the cone ellipsoid, close to the oil droplet (Figure 1B) with a paraboloid that consists of an aggregation of granules (Figure 1B).

\section{Morphology of Retinal Photoreceptors in P. dolloi}

The dimensions of photoreceptor types are summarized in Table 2. Based on morphology, intracellular characteristics and size, juvenile $P$. dolloi possesses one type of rod and at least two types of cones (one with a red oil droplet [red cone] and one lacking an oil droplet [clear cone]). The rod photoreceptors possessed the typical spherule shape, while cones possessed pedicles with a higher number of synaptic ribbons. There is one example of an additional cone type that contained a yellow pigment within the oil droplet, but there are only 36 cells of this type counted in the retina, so it is unknown if this represents a population of a different, rare cone type or oxidation of the red pigment contained in the red cone oil droplets after enucleation. Like all other lungfish species described, most of the cell types within the retina of a juvenile $P$. dollo $i$ are large (147.2 \pm 17.9 $\mu \mathrm{m}$ thick in a $20.6 \mathrm{~cm}$ TL individual, $n=6$, Figure 2 ). No double cones were observed.

The rods are large $(16.0 \pm 2.1 \mu \mathrm{m}$ outer segment length; $n=32$, and $11.7 \pm 1.3 \mu \mathrm{m}$ ellipsoid diameter; $n=34$, in a $20.6 \mathrm{~cm}$ TL individual) and contain one large oil droplet situated within the sclerad section of the ellipsoid of the inner segment amongst the mitochondria (118.4 $\pm 23.6 \mu \mathrm{m}^{2}$ oil droplet area, $n=33$ ), and unlike L. paradoxa, a number of smaller oil droplets (between 0 and $5, n=12$ ) are situated closer to the nucleus (Figure 3A). The outer segment is cylindrical in shape, and consists of scalloped discs surrounded by a plasma membrane (Figure 3B). The presence of rods is confirmed by the presence of incisures in the outer segment discs (Figure 3C). There are also unknown inclusions within the rod outer segment (Figure 3A). The ellipsoid of the rod is similar to that of $L$. paradoxa and consists of electron-dense, tightly packed mitochondria of various shapes and sizes that become smaller toward the nucleus (outer nuclear layer), and lack discernible internal structure apart from a few remaining cristae. A large paraboloid containing

TABLE 1 | Photoreceptor dimensions of adult Lepidosiren paradoxa ${ }^{\mathrm{a}}$.

\begin{tabular}{|c|c|c|c|c|c|c|}
\hline & $\begin{array}{c}\text { Basal diameter of } \\
\text { outer segment (OS) ( } \mu \mathrm{m})\end{array}$ & $\begin{array}{l}\text { Length of } \\
\text { os }(\mu \mathrm{m})\end{array}$ & $\begin{array}{c}\text { Diameter of } \\
\text { ellipsoid }(\mu \mathrm{m})\end{array}$ & $\begin{array}{l}\text { Length of } \\
\text { ellipsoid }(\mu \mathrm{m})\end{array}$ & $\begin{array}{l}\text { Oil droplet (OD) } \\
\text { (Present/Absent) }\end{array}$ & $\begin{array}{c}\text { Size of } \\
\text { OD }\left(\mu \mathrm{m}^{2}\right)\end{array}$ \\
\hline Rod & $10.1 \pm 0.8(14)$ & $8.0 \pm 1.4(13)$ & $18.0 \pm 1.8(13)$ & $27.7 \pm 4.1(10)$ & Present & $268.7 \pm 51.0(12)$ \\
\hline Cone & $7.5 \pm 0.7(16)$ & $13.6 \pm 2.8(15)$ & $10.5 \pm 1.8(10)$ & $22.7 \pm 2.4(6)$ & Present & $82.8 \pm 22.0(7)$ \\
\hline
\end{tabular}

${ }^{a}$ All values are the mean \pm one standard deviation with number of cells sampled in parentheses. All measurements are from one individual $96 \mathrm{~cm}$ in $T L$. 


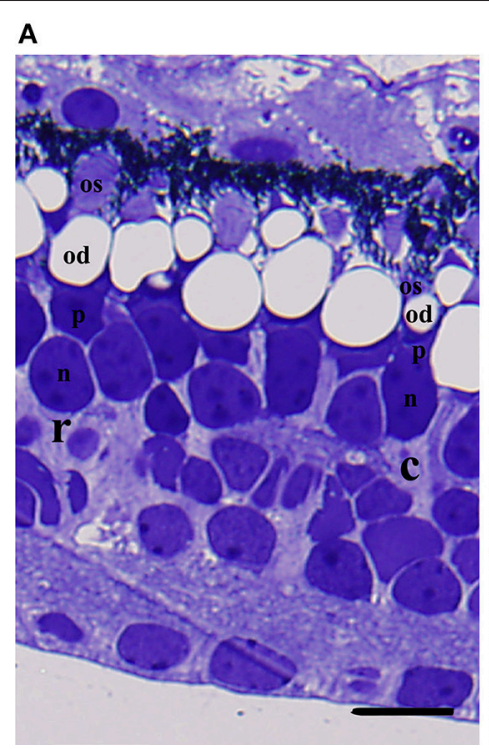

B

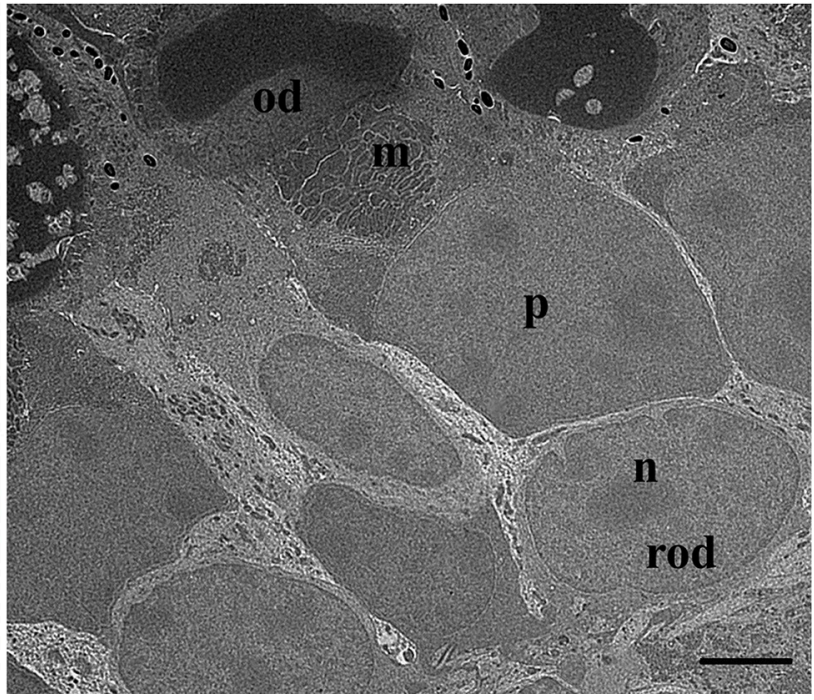

FIGURE 1 | Morphological characteristics of rod and cone photoreceptors in adult Lepidosiren paradoxa. (A) Light micrograph of retina in transverse section showing the rod ( $r$ ) and cone (c) photoreceptor. The rod outer segment (os) is cylindrical, as opposed to the conical, taped cone outer segment. The oil droplet (od) of the rod is much larger than in the cone. Both photoreceptor types contain a paraboloid (p) and nucleus (n) below the oil droplet. Scale bar $=25 \mu \mathrm{m}$ (B) Electron micrograph of a rod. The oil droplet has inclusions that are considered to be artifacts because of their absence in light micrograph. The majority of mitochondria $(\mathrm{m})$ is situated in between the oil droplet (od) and paraboloid $(\mathrm{p})$ and is located centrally, containing electron dense mitochondria of varying shapes and sizes. The nucleus $(\mathrm{n})$ is below the paraboloid, and the cylindrical outer segment (os) is partially obscured. Scale bar $=5 \mu \mathrm{m}$.

TABLE 2 | Photoreceptor dimensions and characteristics of juvenile Protopterus dolloia .

\begin{tabular}{lcccccc}
\hline & $\begin{array}{c}\text { Basal diameter of } \\
\text { outer segment }(\mathbf{O S})(\boldsymbol{\mu m})\end{array}$ & $\begin{array}{c}\text { Length of } \\
\text { OS }(\mu \mathrm{m})\end{array}$ & $\begin{array}{c}\text { Diameter of } \\
\text { ellipsoid }(\mu \mathrm{m})\end{array}$ & $\begin{array}{c}\text { Length of } \\
\text { ellipsoid }(\mu \mathrm{m})\end{array}$ & $\begin{array}{c}\text { Oil droplet (OD) } \\
(\text { Present/Absent) }\end{array}$ & $\begin{array}{c}\text { Size of } \\
\text { OD }\left(\mu \mathbf{m}^{2}\right)\end{array}$ \\
\hline Rod & $9.2 \pm 1.0(32)$ & $16.0 \pm 2.1(32)$ & $11.7 \pm 1.3(34)$ & $22.2 \pm 2.7(33)$ & Present & $118.4 \pm 23.6^{\star}(33)$ \\
Red cone & $4.7 \pm 0.8(15)$ & $6.4 \pm 0.7(14)$ & $7.4 \pm 1.8(14)$ & $12.7 \pm 2.0(12)$ & Present & $39.0 \pm 10.3(13)$ \\
Clear cone & $3.8 \pm 1.0(13)$ & $5.6 \pm 1.4(13)$ & $9.1 \pm 1.0(15)$ & $12.3 \pm 0.7(14)$ & Absent & N/A \\
\hline
\end{tabular}

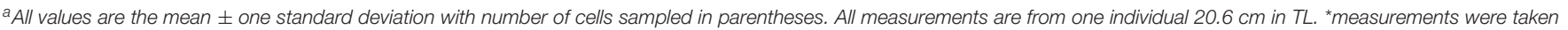
of largest oil droplet in the rod.

an aggregation of granules lies between the mitochondria and nucleus of the rod, but unlike L. paradoxa, there is a space (that may be an artifact) between the mitochondria and nucleus (Figure 3A).

Two morphologically different cone types were identified in $P$. dolloi in retinal wholemount, and using light and electron microscopy based on inclusions within the inner segment of the photoreceptors; a cone with a red oil droplet (red cone; Figure 4A), and a cone with no oil droplet (clear cone; Figure 4C).

The red cone contains a large red oil droplet within the ellipsoid of the inner segment (Figure 4B). The outer segment is conical in shape, with a basal diameter of $4.7 \pm 0.8 \mu \mathrm{m}(n=15)$ and length of $6.4 \pm 0.7 \mu \mathrm{m}(n=14)$. The diameter of the ellipsoid is $7.4 \pm 1.8 \mu \mathrm{m}(n=14)$ and is filled with a single red oil droplet $\left(39.0 \pm 10.3 \mu \mathrm{m}^{2}, n=13\right)$ in size (Table 2). The mitochondria within the ellipsoid have a similar organization to the mitochondria in the rods, where larger mitochondria are concentrated toward the oil droplet and decrease in size closer to the nucleus (Figure 4B). In this individual, eleven smaller cones with a small red oil droplet were counted along the nasal edge of the retina. These may be red cones that were damaged by tissue fixation and/or processing or a developmental stage of the red cone receptor type as they resemble the large red-oil droplet bearing cones in all other characteristics.

The cone without an oil droplet has a tapered, conical outer segment with a basal diameter of $3.8 \pm 1.0 \mu \mathrm{m}(n=13)$ and a length of $5.6 \pm 1.4 \mu \mathrm{m}(n=13)$ in an individual of $20.6 \mathrm{~cm}$ in TL. The ellipsoid is $9.1 \pm 1.0 \mu \mathrm{m}(n=15)$ in diameter and is filled with mitochondria of varying sizes, the largest of which are positioned closest to the outer segment (Figure 4C). Like the rods, the paraboloid of the clear cone consists of granules that sit between the mitochondria and nucleus.

\section{Topographic Distribution of the Red-Oil Droplet Bearing Photoreceptor Type in P. dolloi}

The photoreceptors of the juvenile $P$. dolloi are tightly packed across the retina. There does not appear to be a geometrically 


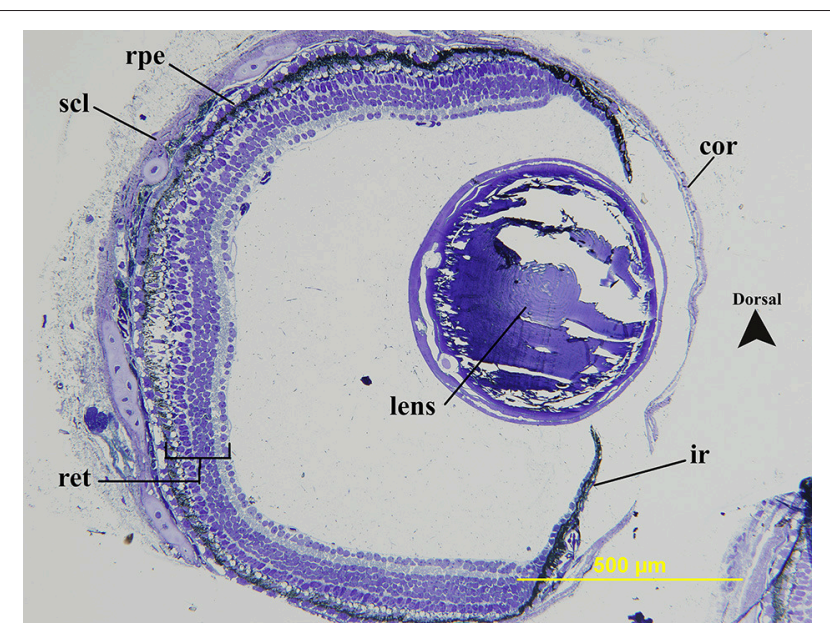

FIGURE 2 | Transverse section of the geometric center of a juvenile Protopterus dolloi eye. The sclera (scl) surrounds the back of the eye to become the cornea (cor) anteriorly. The lens is spherical and relatively large in the eyecup and sits more dorsally, with the iris (ir) length being unequal on either side of the lens. The retinal pigment epithelium is darkly pigmented (rpe). All retinal (ret) cell layers are present.

regular photoreceptor mosaic, but no formal analysis of photoreceptor spacing was undertaken. However, the red cones often lie adjacent to each other, in the middle of five other photoreceptors, usually rods (Figure 4A). The topographic distribution of red cones in juvenile $P$. dolloi shows regional variation, with a dorso-nasal area centralis in the retina with a peak density of $1.4 \times 10^{3}$ cells $\mathrm{mm}^{-2}$ and a total red cone population of $837 \times 10^{3}$ cells in an individual of $20.2 \mathrm{~cm}$ in TL (Figure 5).

\section{DISCUSSION}

This study reveals the presence and ultrastructure of one rod and two cone photoreceptor types in juvenile $P$. dolloi, the topographical distribution of the red cone in a juvenile $P$. dolloi, and the characterization of one rod and one cone type in adult $L$. paradoxa. Like the photoreceptors of $N$. forsteri, the photoreceptors of $P$. dolloi and L. paradoxa are large in absolute terms and their large inner segment cross sectional area and outer segment length will aid in maximizing photon capture in dim light. This has been confirmed behaviorally in the cichlid (Haplochromis sauvagei) where an increase in photic sensitivity is associated with increased photoreceptor size (Van der Meer, 1994).

\section{Photoreceptor Types in $L$. paradoxa}

This study showed L. paradoxa possesses one rod and one cone photoreceptor type. This is in accordance with the description by Ali and Anctil (1973) using light microscopy and Zeiss et al. (2011) using immunohistochemistry that identified the presence of LWS cones but no SWS cones. However, no immunostaining for MWS cones was undertaken (Zeiss et al., 2011). During aestivation, L. paradoxa remains dormant and does not feed during the dry, winter months that can potentially last for 8 months a year. This is unlike the lifestyle of $P$. dolloi, which make frequent journeys to the top of their burrows during aestivation to breathe, and N. forsteri that do not aestivate at all. These disparate lifestyles may have resulted in less dependency on color vision, as L. paradoxa is frequently described as the least fishlike, with the least developed retina (Ali and Anctil, 1973), but precisely what the role of color vision is in all lungfish species is still a matter of speculation.

The morphology of the oil droplet bearing rod and cone photoreceptors in L. paradoxa closely resembles those of P. dolloi, and follows what was described in an ultrastructural study by Ali and Anctil (1973). However, Zeiss et al. (2011) described the rods of L. paradoxa as containing an ellipsoid without an oil droplet. This finding is in contrast with Ali and Anctil's (1973) report on rods despite specimens being processed in the same way. In processing the L. paradoxa retina for this study, unknown inclusions within the oil droplets of rods and cones appeared in the transmission electron micrographs. This may be an artifact, or may indicate a difference in the composition of the ellipsoid and/or the oil droplet in the photoreceptors in comparison to $P$. dolloi. In order to determine if the inclusions within the inner segment of $L$. paradoxa photoreceptors are oil droplets, the retina can be stained with Oil Red $\mathrm{O}$ to show the presence of neutral fats (triglycerides), as was carried out with $N$. forsteri (Bailes et al., 2006).

Of all lungfishes, $N$. forsteri is the only known species that does not possess oil droplets in their rod photoreceptors. Many species of vertebrates contain colorless oil droplets, such as the turtle Pseudymys scripta (Kolb and Jones, 1987), the green frog Rana clamitans (Hailman, 1976), and the strawberry poison frog Dendrobates pumilio (Siddiqi et al., 2004). It is speculated that retinal oil droplets were originally colored, but where species have subsequently become nocturnal these pigments were lost (Hart et al., 2006). This is presumably because the benefits of spectral tuning conferred by colored oil droplets are outweighed by the reduction in absolute sensitivity that would make vision in dim light more difficult. Chickens (Gallus gallus domesticus) reared in dim light develop less dense pigmentation in their colored oil droplets compared to those reared in bright light, presumably to maintain absolute sensitivity at the expense of spectral tuning (Hart et al., 2006), so it may be possible that adopting nocturnality provided the selective pressure to lose colored pigments within oil droplets. All oil droplets can potentially act as micro-lenses to increase photon capture (Sivak et al., 1999); although more research is needed to determine what role they play in P. dolloi and L. paradoxa.

\section{Photoreceptor Types in P. dolloi}

The photoreceptors of the juvenile $P$. dolloi contain at least one type of rod and two types of cones (red oil droplet containing cones and clear, no oil droplet containing cones) that suggest it has the potential for dichromatic color vision. The photoreceptors are not arranged in a regular mosaic, like N. forsteri and L. paradoxa (Ali and Anctil, 1973; Bailes et al., 2006). The description of oil droplet containing rods, and cones with and without oil droplets is in accordance with Pfeiffer 

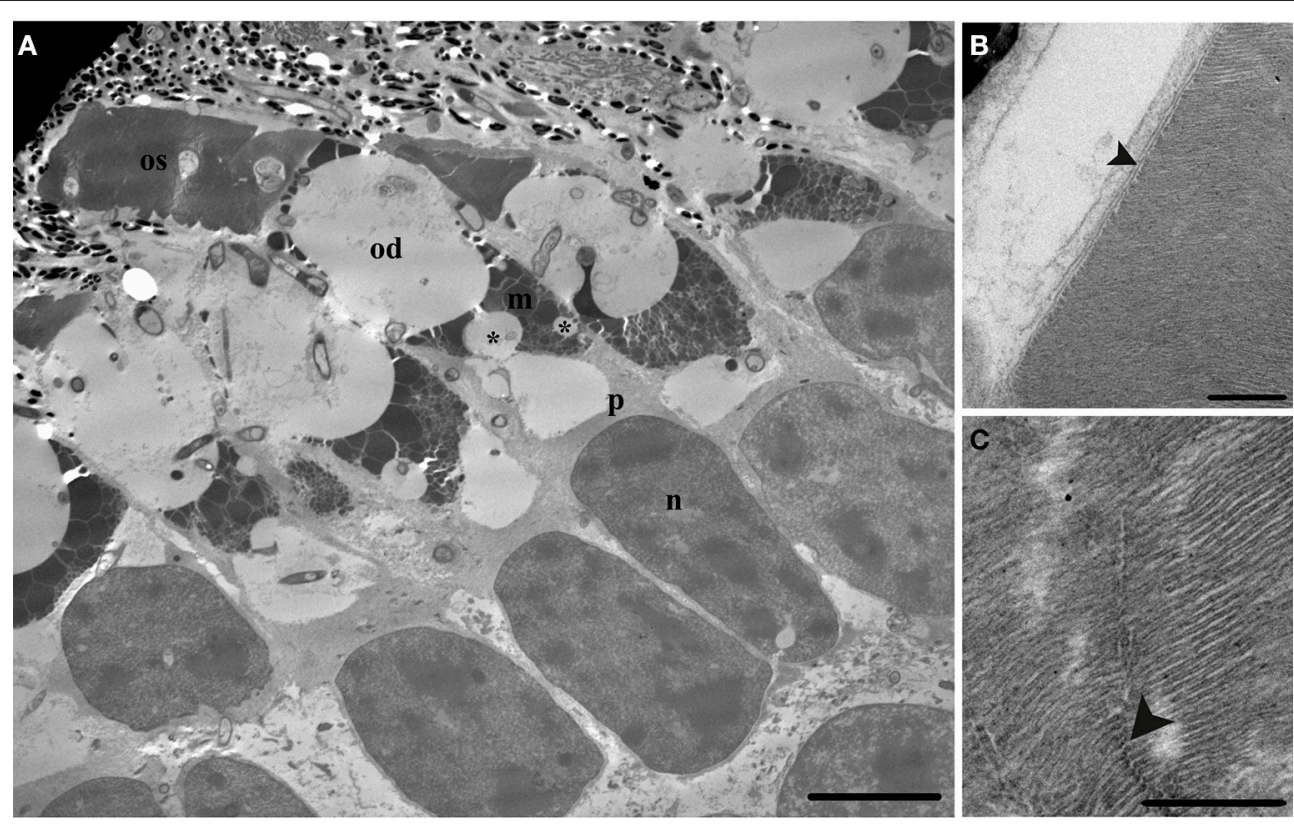

FIGURE 3 | Transmission electron micrographs detailing the ultrastructure of a juvenile Protopterus dolloi rod photoreceptor. (A) The rod (rd) is large with one large oil droplet (od) situated within the mitochondria $(\mathrm{m})$ of the ellipsoid, with smaller oil droplets $\left(^{*}\right)$ in the mitochondria, closer to the paraboloid $(\mathrm{p})$. The nucleus ( $\mathrm{n}$ ) is elongated, and the outer segment (os) is cylindrical in shape, containing unknown inclusions (arrowhead). Scale bar $=10 \mu \mathrm{m}$. (B) The outer segment consists of scalloped discs (arrowhead) surrounded by a plasma membrane. Scale bar $=0.5 \mu \mathrm{m}$. (C) The rods are confirmed by the presence of incisures (arrowhead), which appear as gaps in the discs of the outer segment. Scale bar $=0.25 \mu \mathrm{m}$.

(1968). However, our investigation did not reveal double cones. Pfeiffer (1968) described the retina of $P$. dolloi in paraffin wax sections, and reported single cones with oil droplets, and double cones with only one member containing an oil droplet. Our investigation of $P$. dolloi photoreceptors did not show a clear cone next to a cone of a different type that was not another clear cone, rod, or red cone. In fact, there were many occasions where two clear cones were situated next to each other. Ali and Anctil's (1973) description of L. paradoxa photoreceptors from tissue processed in paraffin wax did note the presence of pairs of visual cells that may have been unequal double cones. However, they concluded that these instances were random associations of a single cone and rod (Ali and Anctil, 1973). Without a reference image of $P$. dolloi double cones from Pfeiffer (1968), this is difficult to confirm. Double cones are present in many teleost fishes (Stell and Hárosi, 1976; Collin, 1997; Collin and Shand, 2003; Pignatelli et al., 2010), and most terrestrial vertebrates such as birds (Hart, 2001), amphibians (Mariani, 1986), and diurnal reptiles (Detwiler and Laurens, 1920; Sillman et al., 1997), and some marsupials and monotremes (Young and Pettigrew, 1991; Ahnelt and Kolb, 2000; Ebrey and Koutalos, 2001). The function of double cones is still under consideration, but there is evidence that they aid in the detection of motion and discrimination in fine spatial detail rather than chromatic visual tasks in birds (for review see Hart and Hunt, 2007) but are involved in color discrimination in reef teleosts such as Rhinecanthus aculeatus (Pignatelli et al., 2010). In dipnoans, $N$. forsteri and L. paradoxa do not possess double cones, while double cones are unconfirmed in Protopterus annectens and Protopterus amphibius. The only species with described double cones is Protopterus aethiopicus. P. aethiopicus and P. annectens are the "youngest" members of the extant lungfishes in the Lepidosirenidae family, and are more closely related to each other than L. paradoxa, P. dolloi or P. amphibius. The lack of double cones in N. forsteri, L. paradoxa, and now P. dolloi, suggests that they may have evolved after the evolutionary separation from $P$. dolloi. However, until the photoreceptors in $P$. annectens and $P$. amphibius have been described in greater detail, the reason is uncertain because visual specializations or degeneracy in species is greatly dependent on environmental pressures.

The red cones of $P$. dolloi have a similar appearance to the red cones present in $N$. forsteri. Colored oil droplets tend to act as long-pass cut-off filters, selectively transmitting longer wavelengths of light and blocking shorter wavelengths. The spectral location of the cut-off varies, but in general their effect is to narrow the spectral sensitivity function of the cones while simultaneously increasing color discrimination (by increasing contrast between adjacent spectral photoreceptor types; Vorobyev, 2003). Without decreasing the total amount of ambient light entering the eye through a colored lens, as in humans, colored oil droplets allow an animal to utilize almost all the light available for vision without sacrificing clarity (Bowmaker, 1980). In N. forsteri, the red cone oil droplet absorbs all wavelengths below about $560 \mathrm{~nm}$ and, along with the yellow pigmented cone type, improves the animals' ability 


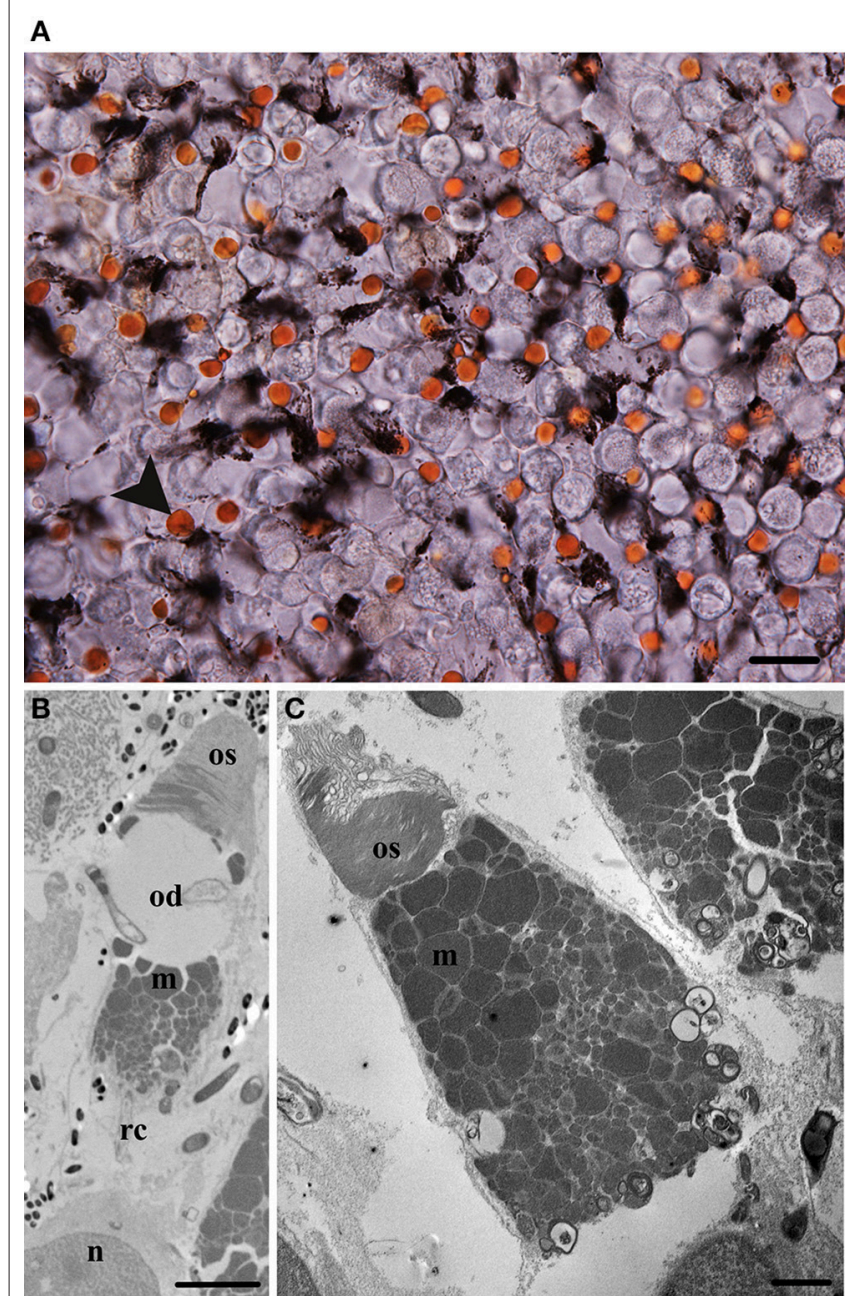

FIGURE 4 | Morphological characteristics of cone photoreceptors in juvenile Protopterus dolloi. (A) Retinal wholemount of an unstained P. dolloi retina showing the red cones (arrowhead) at the level of the ellipsoid. Scale bar $=20 \mu \mathrm{m}$. (B) Electron micrograph showing the ultrastructure of a red cone (rc). The outer segment (os) is tapered with an oil droplet (od) located in the ellipsoid region above the majority of mitochondria $(m)$, with the nucleus $(n)$ more vitread. Scale bar $=5 \mu \mathrm{m}$ (C) Electron micrograph of the outer segment (os) and mitochondria (m) containing the ellipsoid of the clear cone. Scale bar $=2 \mu \mathrm{m}$

to discriminate colors by a factor of $\sim 1.3$ which may aid their discrimination of foliage, prey items, conspecifics, and potential predators (Hart et al., 2008). However, this assumes that we understand the visual tasks that have driven the evolution of the eye in $N$. forsteri. Until the spectral absorption characteristics of the visual pigments and oil droplets of $P$. dolloi are measured, it is impossible to assess how much the inclusion of red oil droplets in one cone type improves color discrimination. Nevertheless, the presence of red cones in $P$. dolloi suggests that greater discrimination of objects at long wavelengths is an adaptation required for animals living in freshwater rivers and swampland where substantial sediment and mineral deposits reflect light in the red part of the visible spectrum (Hart et al., 2008).

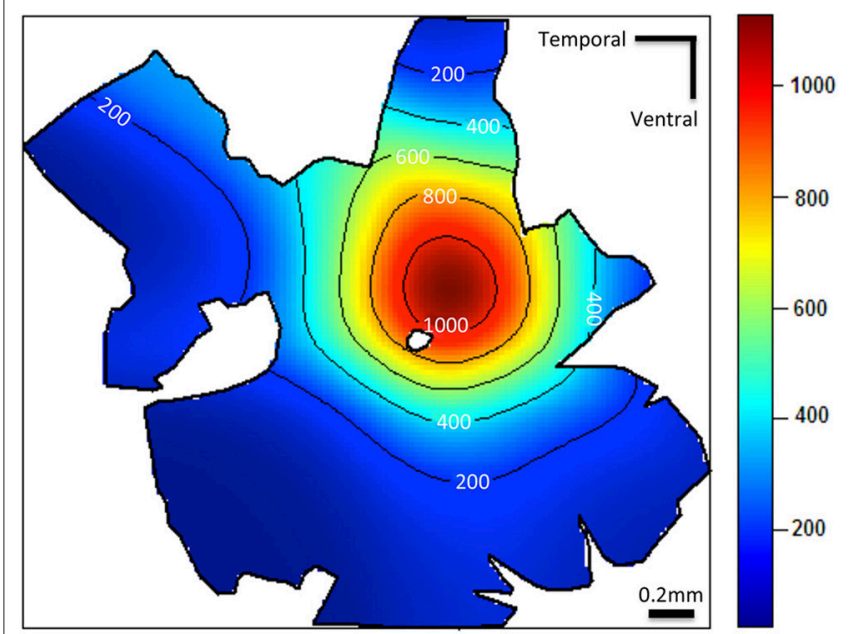

FIGURE 5 | Topographic density map of the red cone photoreceptors $\left(\mathrm{mm}^{2}\right)$ in a juvenile Protopterus dolloi $20.2 \mathrm{~cm}$ in TL. Note that the greatest density of red cones is located centrally in the dorso-nasal region of the retina.

The area centralis of the red cones of $P$. dolloi is located on the central edge of the dorso-nasal quadrant, which provides acute vision within the ventral and lateral visual field where predators would be encountered, especially given the side-toside movements of the body/head. In the African lungfish P. aethiopicus (Curry-Lindahl, 1956; Greenwood, 1987), an acute zone directed forward and into eccentric visual space may aid navigation between tight spaces in the dense vegetation of the swamp (Collin and Pettigrew, 1988). This is similar to the topographic distribution of the cones in $N$. forsteri that indicates a downwardly directed visual axis in juveniles (Bailes et al., 2006). Further study is required to investigate if this increased resolving power in the dorso-nasal region of the visual field is also reflected in other photoreceptor types and within the ganglion cell population thereby providing a better indication of how retinal structures reflects their visual ecology.

\section{CONCLUSION}

This study has revealed that the retina of juvenile $P$. dolloi contains one rod and two morphologically distinct cone photoreceptor types, with increased spatial resolving power in the dorso-nasal region of the retina based on the topographical distribution of the red cones. It has also characterized one rod and one cone type in adult L. paradoxa. The large size of the photoreceptors and the presence of oil droplets in P. dolloi and $L$. paradoxa closely resembles the situation in $N$. forsteri, despite the lack of aestivation in the Australian species, and suggests a visual system that is adapted for high sensitivity, while the presence of one cone photoreceptor type infers that L. paradoxa is the only lungfish species described without the potential for color vision. However, further study is needed to establish the importance of color discrimination, and the selective pressures 
involved in the specializations of the retina of $P$. dolloi and $L$. paradoxa in order to establish the role vision plays in these species' behavioral ecology.

\section{AUTHOR CONTRIBUTIONS}

SC and NH conceived the study; SC, NH, and AA designed the experiments; $\mathrm{AA}$ and $\mathrm{SC}$ carried out the research and analyzed the results. AA, SC, $\mathrm{NH}$, and IZ wrote the manuscript and all authors were involved in the revision of the manuscript and have agreed to the final content.

\section{REFERENCES}

Ahnelt, P. K., and Kolb, H. (2000). The mammalian photoreceptor mosaicadaptive design. Prog. Retin. Eye Res. 19, 711-777. doi: 10.1016/S13509462(00)00012-4

Ali, M. A., and Anctil, M. (1973). Retina of the South American lungfish, Lepidosiren paradoxa Fitzinger. Can. J. Zool. 51, 969-972. doi: 10.1139/z73-140

Amemyia, C. T., Alföldi, J., Lee, A. P., Fan, S., Philippe, H., MacCallum, I., et al. (2013). The African coelacanth genome provides insights into tetrapod evolution. Nature 496, 311-316. doi: 10.1038/nature12027

Bailes, H. J., Robinson, S., Trezise, A. E. O., and Collin, S. P. (2006). Morphology, characterization, and distribution of retinal photoreceptors in the Australian lungfish Neoceratodus forsteri (Krefft, 1870). J. Comp. Neurol. 494, 381-397. doi: 10.1002/cne.20809

Bailes, H. J., Trezise, A. E. O., and Collin, S. P. (2007). The optics of the growing lungfish eye: lens shape, focal ratio and pupillary movements in Neoceratodus forsteri. Vis. Neurosci. 24, 377-387. doi: 10.1017/S0952523807070381

Bemis, W. E., Burggren, W. W., and Kemp, N. E. (1987). The Biology and Evolution of Lungfishes. New York, NY: Alan R. Liss.

Bowmaker, J. (1980). Colour vision in birds and the role of oil droplets. Trends Neurosci. 3, 196-199. doi: 10.1016/0166-2236(80)90072-7

Brinkmann, H., Venkatesh, B., Brenner, S. and Meyer, A. (2004). Nuclear proteincoding genes support lungfish and not the coelacanth as the closest living relatives of land vertebrates. Proc. Natl. Acad. Sci. U.S.A. 101, 4900-4905. doi: 10.1073/pnas.0400609101

Carter, G., and Beadle, L. (1930). Notes on the habits and development of Lepidosiren paradoxa. J. Linn. Soc. Lond. 37, 197-203. doi: 10.1111/j.10963642.1930.tb02065.x

Clack, J. A., Sharp, E. L., and Long, J. A. (2011). "The fossil record of lungfishes," in The Biology Of Lungfishes, eds J. M. Jorgensen and J. Joss. (Enfield: Science Publishers), 1-42.

Coimbra, J. P., Marceliano, M., Andrade-da-Costa, B., and Yamada, E. S. (2006). The retina of tyrant flycatchers: topographic organization of neuronal density and size in the ganglion cell layer of the great kiskadee Pitangus sulphuratus and the rusty margined flycatcher Myiozetetes cayanensis (Aves: Tyrannidae). Brain Behav. Evol. 68, 15-25. doi: 10.1159/000092310

Coimbra, J. P., Trévia, N., Marceliano, M. L. V., Andrade-Da-Costa, B. L. S., Picanço-Diniz, C. W., and Yamada E. S. (2009). Number and distribution of neurons in the retinal ganglion cell layer in relation to foraging behaviors of tyrant flycatchers. J. Comp. Neurol. 514, 66-73. doi: 10.1002/cne.21992

Collin, S. (1999). "Behavioural ecology and retinal cell topography," in Adaptive Mechanisms in the Ecology of Vision, eds S. Vallerga and M. B. Djamgoz (Boston, MA: Springer), 509-535.

Collin, S. P. (1997). Specialisations of the teleost visual system: adaptive diversity from shallow-water to deep-sea. Acta Physiol. Scand. Suppl. 638, 5-24.

Collin, S. P. (2010). Evolution and ecology of retinal photoreception in early vertebrates. Brain Behav. Evol. 75, 174-185. doi: 10.1159/000314904

Collin, S. P., and Collin, H. (2001). "The fish cornea: adaptations for different aquatic environments," in Sensory Biology of Jawed Fishes New Insights, eds B. G. Kapoor and T. J. Hara (Plymoth: Science Publishers), 57-96.

\section{ACKNOWLEDGMENTS}

The authors thank Michael Archer and the Centre for Microscopy, Characterization and Analysis, UWA for assistance with training and processing for scanning electron microscopy. We are grateful to Dr. Guido Westhoff from the University of Bonn, Germany and Prof. Glenn Northcutt from the University of California, San Diego (UCSD), USA for their kind donation of lungfish tissue samples. Financial support from the Australian Research Council, the Western Australian Government, and the University of Western Australia is also acknowledged.

Collin, S. P., and Pettigrew, J. (1988). Retinal topography in reef teleosts. Brain Behav. Evol. 31, 269-282. doi: 10.1159/000116594

Collin, S. P., and Shand, J. (2003). "Retinal sampling and the visual field in fishes," in Sensory Processing in Aquatic Environments, eds S. P. Collin and J. N. Marshall (New York, NY: Springer), 139-169.

Curry-Lindahl, K. (1956). On the ecology, feeding behaviour and territoriality of the African lungfish, Protopterus aethiopicus Heckel. Arkiv Zool. 9, 479-497.

Dean, B. (1906). Notes on the living specimens of the Australian lungfish, Ceratodus forsteri, in the Zoological Society's collection. Proc. Zool. Soc. Lond. 76, 168-178. doi: 10.1111/j.1469-7998.1906.tb08428.x

Dean, B. (1912). Additional notes on the living specimens of the Australian lungfish (Ceratodus forsteri) in the Zoological Society's collection. Proc.Zool. Soc. Lond. 1912, 607-612.

Detwiler, S. R., and Laurens, H. (1920). Studies on the retina. The structure of the retina of Phrynosoma cornutum. J. Comp. Neurol. 32, 347-356. doi: $10.1002 / \mathrm{cne} .900320305$

Ebrey, T., and Koutalos, Y. (2001). Vertebrate photoreceptors. Prog. Retin. Eye Res. 20, 49-94. doi: 10.1016/S1350-9462(00)00014-8

Fonesca de Almeida-Val, V., Nozawa, S., Lopes, N., Aride, P., Mesquita-Saad, L., Mazare Paula da Silva, M., et al. (2011). "Biology of the South American lungfish, Lepidosiren paradoxa," in The Biology of Lungfishes, eds J. Jorgensen and J. Joss (Enfield: Science Publishers), 129-148.

Garza-Gisholt, E., Hemmi, J. M., Hart, N. S. and Collin, S. P. (2014). A comparison of spatial analysis methods for the construction of topographic maps of retinal cell density. PLoS One 9:e93485. doi: 10.1371/journal.pone.0093485

Greenwood, P. (1987). "The natural history of African lungfishes," in The Biology and Evolution of Lungfishes, eds W. E. Bemis, W. W. Burggren, and N. E. Kemp (New York, NY: Alan R. Liss Inc.), 163-181.

Greenwood, P. H. (1986). The natural history of African lungfishes. J. Morphol. 190, 163-179. doi: 10.1002/jmor.1051900412

Grigg, G. C. (1965). Studies on the Queensland lungfish, Neoceratodus forsteri (Krefft). 3. Aerial respiration in relation to habits. Aust. J. Zool. 13, 413-422. doi: $10.1071 /$ ZO9650413

Hailman, J. P. (1976). Oildroplets in the eyes of adult anuran amphibians: a comparative survey. J. Morphol. 148, 453-468. doi: 10.1002/jmor.1051480404

Hart, N. S. (2001). The visual ecology of avian photoreceptors. Prog. Retin. Eye Res. 20, 675-703. doi: 10.1016/S1350-9462(01)00009-X

Hart, N. S., Bailes, H. J., Vorobyev, M., Marshall, N. J., and Collin, S. P. (2008). Visual ecology of the Australian lungfish (Neoceratodus forsteri). BMC Ecol. 8:21. doi: 10.1186/1472-6785-8-21

Hart, N. S., and Hunt, D. M. (2007). Avian visual pigments: Characteristics, spectral tuning, and evolution. Am. Nat. 169, S7-S26. doi: 10.1086/510141

Hart, N. S., Lisney, T. J., and Collin, S. P. (2006). Cone photoreceptor oil droplet pigmentation is affected by ambient light intensity. J. Exp. Biol. 209, 4776. doi: 10.1242/jeb.02568

Johnels, A., and Svensson, G. (1954). On the biology of Protopterus annectens (Owen). Arkiv Zool. 7, 131-164.

Kemp, A. (1986). The biology of the Australian lungfish, Neoceratodus forsteri (Krefft 1870). J. Morphol. 190, 181-198. doi: 10.1002/jmor.1051900413 
Kemp, A., and Molnar, R. (1981). Neoceratodus forsteri from the Lower Cretaceous of New South Wales, Australia. J. Paleontol. 55, 211-217.

Kerr, J. (1902). The development of Lepidosiren paradoxa. III. Development of the skin and its derivatives. Q. J. Microsc. Sci. 46, 417-459.

Kolb, H., and Jones, J. (1987). The distinction by light and electron microscopy of two types of cone containing colorless oil droplets in the retina of the turtle. Vision Res. 27, 1445-1458. doi: 10.1016/0042-6989(87)90154-4

Mariani, A. (1986). Photoreceptors of the larval tiger salamander retina. Proc. $R$. Soc. Lond. B Biol. Sci. 227, 483-492. doi: 10.1098/rspb.1986.0035

Marshall, C. R. (1986). A list of fossil and extant dipnoans. J. Morphol. 190, 15-23. doi: 10.1002/jmor.1051900405

Mlewa, C., Green, J., and Dunbrack, R. (2011). "The general natural history of African lungfishes," in The Biology of Lungfishes, eds J. Jorgensen and J. Joss. (Enfield: Science Publishers), 97-128.

Owen, S. R. (1840). XX. Description of the Lepidosiren annectens. Trans. Linn. Soc. Lond. 18, 327-361. doi: 10.1111/j.1095-8339.1838.tb00182.x

Pfeiffer, W. (1968). Retina und retinomotorik der dipnoi und brachiopterygii. Cell Tissue Res. 89, 62-72. doi: 10.1007/bf00332652

Pignatelli, V., Champ, C., Marshall, J., and Vorobyev, M. (2010). Double cones are used for colour discrimination in the reef fish, Rhinecanthus aculeatus. Biol. Lett. doi: 10.1098/rsbl.2009.1010. Available online at: http://rsbl. royalsocietypublishing.org/content/early/2010/01/28/rsbl.2009.1010.short

Siddiqi, A., Cronin, T. W., Loew, E. R., Vorobyev, M., and Summers, K. (2004), Interspecific and intraspecific views of color signals in the strawberry poison frog Dendrobates pumilio. J. Exp. Biol. 207, 2471-2485. doi: 10.1242/jeb. 01047

Sillman, A., Govardovskii, V., Röhlich, P., Southard, J., and Loew, E. (1997). The photoreceptors and visual pigments of the garter snake (Thamnophis sirtalis): a microspectrophotometric, scanning electron microscopic and immunocytochemical study. J. Comp. Physiol. A 181, 89-101. doi: 10.1007/s003590050096

Sivak, J., Andison, M., and Pardue, M. (1999). "Vertebrate optical structure," in Adaptive Mechanisms in the Ecology of Vision, eds S. Vallerga and M. B. Djamgoz (Boston, MA: Springer), 73-94.
Stell, W. K., and Hárosi, F. I. (1976). Cone structure and visual pigment content in the retina of the goldfish. Vision Res. 16, 647-IN644. doi: 10.1016/00426989(76)90013-4

Stone, J. (1981). The Whole Mount Handbook: A Guide to the Preparation and Analysis of Retinal Whole Mounts. Sydney: Maitland Publications.

Tokita, M., Okamoto, T., and Hikida, T. (2005). Evolutionary history of African lungfish: a hypothesis from molecular phylogeny. Mol. Phylogenet. Evol. 35, 281. doi: 10.1016/j.ympev.2004.11.025

Van der Meer, H. (1994). Ontogenetic change of visual thresholds in the cichlid fish Haplochromis sauvagei. Brain Behav. Evol. 44, 40-49. doi: 10.1159/000113568

Vorobyev, M. (2003). Coloured oil droplets enhance colour discrimination. Proc. R. Soc. Lond. B Biol. Sci. 270, 1255-1261. doi: 10.1098/rspb.2003.2381

Vorobyev, M., Osorio, D., Bennett, A., Marshall, N., and Cuthill, I. (1998). Tetrachromacy, oil droplets and bird plumage colours. J. Comp. Physiol. A 183, 621-633. doi: 10.1007/s003590050286

Walls, G. L. (1942). The Vertebrate Eye and its Adaptive Radiation. Bloomfield Hills: The Cranbook Press.

Young, H. M., and Pettigrew, J. D. (1991). Cone photoreceptors lacking oil droplets in the retina of the echinda, Tachyglossus aculeatus (Monotremata). Vis. Neurosci. 6, 409-420. doi: 10.1017/S0952523800001279

Zeiss, C. J., Schwab, I. R., Murphy, C. J., and Dubielzig, R. W. (2011) Comparative retinal morphology of the platypus. J. Morphol. 272, 949-957. doi: 10.1002/jmor.10959

Conflict of Interest Statement: The authors declare that the research was conducted in the absence of any commercial or financial relationships that could be construed as a potential conflict of interest.

Copyright (c) 2016 Appudurai, Hart, Zurr and Collin. This is an open-access article distributed under the terms of the Creative Commons Attribution License (CC BY). The use, distribution or reproduction in other forums is permitted, provided the original author(s) or licensor are credited and that the original publication in this journal is cited, in accordance with accepted academic practice. No use, distribution or reproduction is permitted which does not comply with these terms. 